\section{$\underset{\substack{\text { hommes } \\ \text { \& migrations }}}{ }$}

\section{Hommes \& migrations}

Revue française de référence sur les dynamiques

migratoires

\section{$1308 \mid 2014$}

Les Paris des migrants

\title{
Paris autrement
}

La fabrique d'une "ville-monde"

\section{Marie Poinsot}

\section{(2) OpenEdition \\ 1 Journals}

Édition électronique

URL : http://journals.openedition.org/hommesmigrations/2981

DOI : 10.4000/hommesmigrations.2981

ISSN : 2262-3353

Éditeur

Musée national de l'histoire de l'immigration

\section{Édition imprimée}

Date de publication : 1 octobre 2014

Pagination : 1

ISBN : 978-2-919040-29-2

ISSN : 1142-852X

\section{Référence électronique}

Marie Poinsot, «Paris autrement », Hommes \& migrations [En ligne], 1308 | 2014, mis en ligne le 23 juin 2015, consulté le 24 septembre 2020. URL : http://journals.openedition.org/hommesmigrations/2981 ; DOI : https://doi.org/10.4000/hommesmigrations.2981 


\section{PARIS AUTREMENT LA FABRIQUE D'UNE "VILLE-MONDE"}

par MARIE POINSOT, rédactrice en chef.

Le passé composé de Paris n'est plus à prouver. La capitale des arts et des lettres a non seulement attiré de tout temps des talents, mais aussi des bras pour construire ses rues, ses immeubles, et pour travailler dans ses usines et ses commerces. Encore aujourd'hui, la Ville regroupe un sixième des étrangers installés en France, dont une majorité née hors de l'Europe.

La revue a voulu revisiter cette présence étrangère, souligner les particularités de son installation sur le territoire francilien et mettre en valeur ses contributions au développement de la capitale. Cette approche transversale se démarque d'une simple mosaïque de quartiers par peuples et cultures, même si une cartographie des espaces résidentiels des étrangers dans la métropole ouvre utilement ce numéro. Avec Michelle Guillon, pionnière dans ce domaine, on comprend que l'histoire de la présence immigrée à Paris est étroitement liée à celle du logement. Avec l'implantation de foyers de migrants et le développement du parc social, les quartiers populaires - des lieux d'accueil ou de transit en raison des opportunités de logements à bas coûts - ont été progressivement rénovés par une politique de lutte contre l'insalubrité. Si certaines enclaves populaires ont été maintenues, beaucoup d'étrangers ont dû partir habiter à la périphérie, tout en conservantleurs commercesetleurshabitudessociales qui dessinent aujourd'hui des centralités très originales. Ces centralités drainent des clientèles bien au-delà des frontières hexagonales et acquièrent une nouvelle visibilité dans l'espace parisien, fruit de logiques plus complexes que l'affichage ethnoexotique qui fait leur attraction. Si les migrants contribuent à la production des espaces parisiens, leurs modes d'appropriation des territoires diffè- rent selon leur profil sociologique et leur statut. Les Paris sont multiples en fonction des histoires migratoires. Il s'avère que la diversité de cet investissement sur la capitale mêle souvent le projet individuel ou familial et les ressources mobilisables par la communauté pour investir dans certains secteurs ou niches économiques (restauration, confection, commerces alimentaires, bazars, etc.). Une des marques de leur fabrique de Paris réside dans l'entreprenariat familial, les petites entreprises de production, les commerces d'import-export, les services en lien avec leurs filières internationales qui les approvisionnent. La "mondialisation de Paris par le bas" est un signe de vitalité économique, de promotion rapide dans la capitale où l'on travaille parfois sans-papiers mais avec le soutien des communautés de rattachement.

La dimension internationale de Paris s'illustre aussi par des migrations qualifiées qui investissent plutôt les quartiers centraux et les banlieues chics. Derrière la façade touristique glamour, le Paris cosmopolite des élites migrantes met en avant la richesse des héritages culturels et artistiques venus du monde entier et constitue une ressource importante dans la concurrence avec d'autres métropoles. Même si elle reste anonyme dans l'espace, l'extranéité qu'endossent volontiers ces migrations socialement aisées (les Japonais, les Américains, certains étudiants) devient un signe de distinction très positif pour Paris. Mais l'attractivité de la capitale (gastronomie, mode, art et artisanat, musique, etc.) reste associée à l'étiquette française.

C'est parce que Paris mise sur ces deux pôles complémentaires que la région francilienne peut rester un carrefour d'échanges, d'informations et d'innovations à l'échelle internationale, et ainsi continuer à concourir dans le peloton des "villes-monde", sans devenir une mégalopole dépourvue d'identité. I 